\title{
EFFECT OF NANO CLAY ON THE MECHANICAL PROPERTIES OF S-GLASS FIBER REINFORCED EPOXY COMPOSITES
}

\author{
N. PRUDHVIRAJ ${ }^{1}$, M. SOMAIAH CHOWDARY ${ }^{2}$ DR. M.S.R. NIRANJAN KUMAR ${ }^{3}$, N. SIVATEJA ${ }^{4}$ \\ ${ }^{1,4}$ PG student, Department of Mechanical Engineering, Prasad V. Potluri Siddhartha Institute of Technology, Kanuru, \\ Vijayawada, Andhra Pradesh, India \\ ${ }^{2,3}$ Department of mechanical Engineering, Prasad V. Potluri Siddhartha Institute of Technology, Kanuru, Vijayawada, Andhra \\ Pradesh, India
}

\begin{abstract}
Composite materials expect an Important activity in various present-day applications. Experts are working on production of new composite materials worldwide to improve the propriety of these materials. Hybrid composites are one of the most Renowned materials that are essentially broadly used and is getting power as a result of factors like flexibility in plan and higher solidarity to weight extent. The new polymer composite is made in which the S-glass fiber is reinforced to the epoxy resin with the utilization of nano fillers at $1 w t \%, 2 w t \%, 3 w t \%$ which are fabricated by direct hand layup technique. It was seen that the composite with 1 wt \% nano clay content showed the advanced tensile and flexural strength. Regardless, the mechanical properties will in general decline with extension of nano clay content from 2 to 3 wt \%, Because the development of filler beyond 1wt\% is the path that there is more fiber matrix work relationship than that of filler-Matrix association.
\end{abstract}

KEYWORDS: Epoxy, S-Glass Fiber, Mechanical Properties, Nano Clay

Received: Jun 08, 2020; Accepted: Jun 28, 2020; Published: Sep 17, 2020; Paper Id.: IJMPERDJUN20201310

\section{INTRODUCTION}

A composite material is a material comprised of at least two materials that are joined in a manner that permits the materials to remain particular and recognizable. Some normal composite materials incorporate solid, fiberglass, mud blocks, and common composites, for example, rock and wood. Composites are characterized into two sorts dependent on a) Matrix Material b) Reinforcing Material.

M.Somaiah Chowdary has named Effect of Nano clay on the Mechanical properties of Polyester and SGlass Fiber (Al), the goal is to analyze the impact of nano clay content on the mechanical and morphological behaviour of S-glass fiber, strengthened in Polyester with nano clay as filler. Five distinct kinds of composites are created by hand layup method utilizing $0 \mathrm{wt} \%$ nanoclay, $1 \mathrm{wt} \%$ nano clay, $3 \mathrm{wt} \%$ nano clay, $5 \mathrm{wt} \%$ nano clay and $7 \mathrm{wt} \%$ nano clay with $40 \% \mathrm{wt}$ fiber, and polyester. The aftereffects of the investigation show that the joining of nano clay significantly affects the mechanical conduct of composites. The ideal stacking of clay in the Polyester/glass fiber composites was achieved at 3wt\%, where the improvement in tensile and bowing properties was seen [1].

P. Srinivas Manikanta has named Evaluation of Mechanical Properties of Banana and S-glass FiberReinforced Hybrid Nano silica Composite The point of the current work is to assess the mechanical properties of banana and S-glass fiber-reinforced hybrid nano silica composite. The glass and other engineered fiber-reinforced 
polyester composites give high when contrasted with the regular fiber-strengthened composite, however their applications are restricted due to the significant expense of creation. Along these lines, to beat the expense of manufacture and to meet the high quality as of engineered composite, another hybrid composite is created by utilizing half of regular fiber and half of manufactured fiber. The new composite is created by reinforcing the stacking layers of woven banana and s-glass filaments with the polyester resin as a matrix and nano silica as filler material. Various examples were set up by changing the stacking sequence of fiber set in the composite and weight level of nano silica powder that is blended into the resin. The creation is finished by the hand layup strategy. The mechanical properties like tensile strength, flexural strength, tensile modulus, and flexural modulus were contemplated. The morphological examination is done through a scanning electron microscope to watch the fibers pull-out, stacking of filaments, and the behaviour of matrix in the hybrid composite. The difference in weight percentage of nano silica and the stacking sequence of fibers in the composite show the improvement in mechanical properties.[2]

De Rosa et al concluded that using the basalt fiber at the top and bottom of the glass laminate improves the postflexural strength of the hybrid composite. However, it finds difficult to arrive at the conclusion from one hybrid to the other, as there is no theoretical framework available to assess the various material parameters. The flexure strength of the glass fiber reinforced polymer composite can be enhanced by incorporating it with E Glass epoxy laminates and making it hybrid polymer composite. Very less research has been conducted in the field of synthetic fiber and natural fiber reinforced composite materials [3].

Nano-particles are currently considered as high-potential filler materials for the development of mechanical and physical properties of polymer matrix composites.[4]. The advantage of the nano scaled particles compared to the micro scaled fillers is their enormous surface area, which can act as interface for stress-transfer. However, a high SSA causes the formation of agglomerates. The agglomerates of the nanocomposite are difficult to separate and to infiltrate with the matrix [5].

Deepak et al investigated the effect of nano clay loading on mechanical properties for coir-polyester composites. They found an increase in the tensile strength of the specimens that has the addition of clay in it. They also found increase in impact energy and compressive strength with the addition of clay in coir-polyester composites [6].

R. Jeyakumar has named Structural, morphological and mechanical conduct of glass fiber reinforced epoxy nano clay composites the mechanical examinations were completed for all the weight percentages of 1,3,5 and $7 \%$ of the epoxy matrix composites. For $5 \%$ reinforced clay composites, the tensile quality and modulus were found to increment by 23.58 and $23.66 \%$ when contrasted with the unfilled composite. Further increment in Nano clay content decreases the tensile properties of nanocomposite. For the flexural quality and modulus for $5 \%$ Nano clay reinforcement, there is an expansion of 34.10 and $53.86 \%$, individually, when contrasted with the unfilled composite. The effect quality for $5 \%$ reinforcement of Nano clay has an expansion of about $29.65 \%$, whereas for all the other compositions it showed a decreasing trend[7].

The effect of addition of nano clay particles on the flame retarding properties of wood-fiber/plastic composites (WPC) were investigated. This study indicated that the structure of nanocomposites and the clay content used had a great impact on the flame retardancy of WPC [8]. Effect of addition of nano clay on the fiber/matrix adhesion in epoxy/glass composites was investigated. In this study, different organically modified clays were added at different weight fractions in the epoxy matrix. The results depicted that the formation of intercalated microstructures due to nano clay led to considerable improvement in mechanical and thermal properties of the epoxy matrix [9]. Kundan Patel, jay Patel, Piyush 
Gohil and Vijay Kumar Chaudhary has investigated the effect of nano clay on mechanical behaviour of bamboo Fiber reinforced polyester composites. They found that the Addition of $1 \%$ of nano clay by weight shows maximum tensile strength $(66.9 \mathrm{MPa})$ which is $55 \%$ higher than the composite without nano clay. The flexural test shows that addition of $1 \%$ of nano clay by weight into matrix gives the maximum flexural strength (127 MPa), which is $88 \%$ higher than the composite without nano clay. As the nano clay loading increases from $1 \%$ to $4 \%$ by weight, the tensile strength and flexural strength both decreases. [10].

In the research work on the mechanical behaviour of synthetic fibers using nano clay as filler material. I have found a scope to do the project on polymer reinforced hybrid composites i.e., the combination of S-glass using nano clay as filler material. So, my objective is to study the Effect of nano clay on the mechanical properties of Epoxy reinforced Sglass composites.

\section{MATERIALS AND METHODS}

\section{Materials}

In present investigation, The S-glass fibers are used for fabricating the composite specimen with epoxy as the matrix and nano clay as filler. The S-glass is obtained from Vruksha composites, Tenali, Guntur[dt]. Epoxy resin i.e. Diglycidyl ether of bisphenol is obtained from Bindu agencies, Vijayawada and the type used is Araldite LY556, nano clay(montmorillonite) is obtained from sigma Aldrich company, Bengaluru.

\section{Epoxy Resin}

Epoxy resins are the for the most part utilized resins. They are a low sub-atomic weight natural fluid which contains epoxide gatherings. It has two individuals in its ring they are carbon and oxygen atoms. The responses of epichlorohydrin with aromatic amines or phenols amines make most epoxies. Filler, hardeners and plasticisers are additionally added to deliver epoxies with a wide scope of properties of effect, thickness, corruption and so forth. In spite of the fact that it is a costlier one than other polymer grids, polymer framework composites are for the most part utilized. Multiple thirds of the polymer matrices which is utilized is epoxy based sort. Its chemical name is Diglycidyl ether of bisphenol and the sort utilized is Araldite LY556.

Table 1: Properties of epoxy

\begin{tabular}{|l|c|}
\hline \multicolumn{1}{|c|}{ Description } & Properties \\
\hline Specific gravity & $1.2 \mathrm{~kg} / \mathrm{m} 3$ \\
\hline Tensile strength & $35-130 \mathrm{MPa}$ \\
\hline Poisson's ratio & 0.37 \\
\hline Compressive strength & $100-200 \mathrm{MPa}$ \\
\hline Elongation & $1-8.5 \%$ \\
\hline Co-efficient of Thermal Expansion & $45-70 * 10-6 / 0 \mathrm{C}$ \\
\hline Water absorption & $0.1-0.4 \%$ \\
\hline
\end{tabular}

\section{S-glass Fiber}

E-Glass has been used extensively in polymer matrix composites, commonly termed "fibreglass". These materials exhibit good mechanical properties; however, these have not been sufficient in some instances. Consequently, the E-glass composition has been modified to produce more desirable properties. A higher stiffness material resulting from this is SGlass. S-Glass has a typical nominal composition of $\mathrm{SiO}_{2} 65 \mathrm{wt} \%, \mathrm{Al}_{2} \mathrm{O}_{3} 25 \mathrm{wt} \%, \mathrm{MgO} 10 \mathrm{wt} \%$. Some other materials may 
also be present at impurity levels.

Table 2: Properties of S-glass fiber

\begin{tabular}{|l|c|}
\hline \multicolumn{1}{|c|}{ Description } & Properties \\
\hline Density & $2.495 \mathrm{mg} / \mathrm{m} 3$ \\
\hline Filament Diameter & $24 \mu \mathrm{m}$ \\
\hline Tensile strength & $4800 \mathrm{Mpa}$ \\
\hline Tensile modulus & $89 \mathrm{Gpa}$ \\
\hline Elongation & $5.7 \%$ \\
\hline
\end{tabular}

\section{Nano Clay}

Nano clay has obtained a lot of interest as reinforcing substances for polymer because of its potentially high element ratio and particular intercalation traits .The small amount addition of Nano clay into polymer matrix reveals unexpected properties together with lowering fuel permeability, improved solvent resistance, being advanced in mechanical properties and thermal stability, and more desirable flame retardant properties.

\section{Preparation of Composite Specimen}

The Epoxy resin was taken into the beaker, Nano clay with different wt \% was mixed with epoxy resin by using a sonicator with duration of $30 \mathrm{~min}$ to obtain a homogeneous mixture. After mixing, modified epoxy solution was mixed with the hardener and stirring was done. Finally, the mixture was poured on to the fiber sheet on both sides using hand layup and left-over night for drying. The laminas were cured under ambient temperature to get the shape as that of the mould cavity. Finally, the samples were cut as per ASTM standards, for tensile testing ASTM D638M-89 and for Flexural testing ASTM D79M-86.

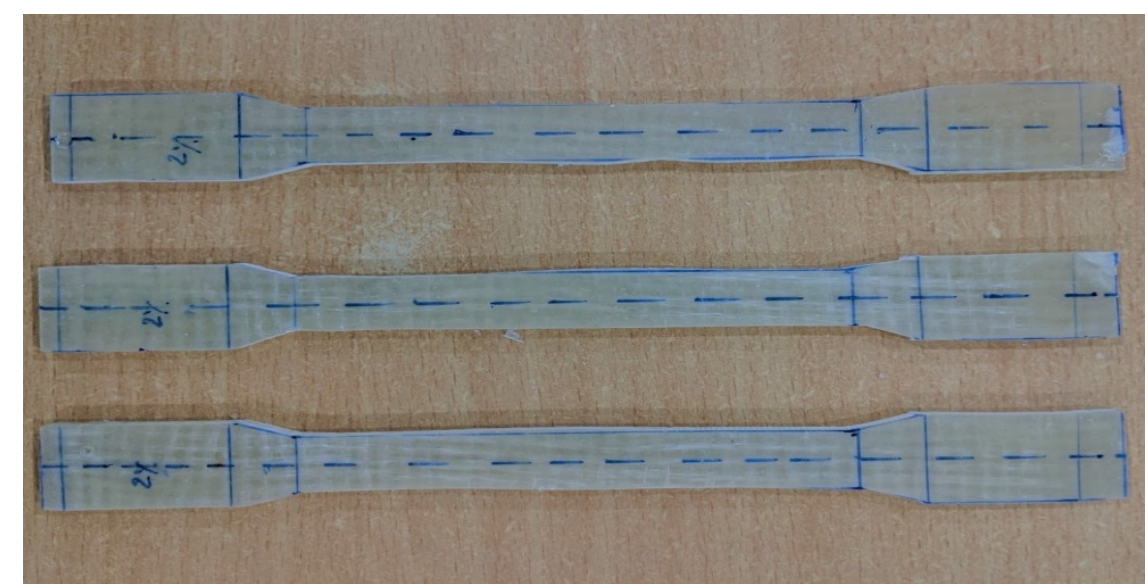

Figure 1: Test specimens before tensile test 


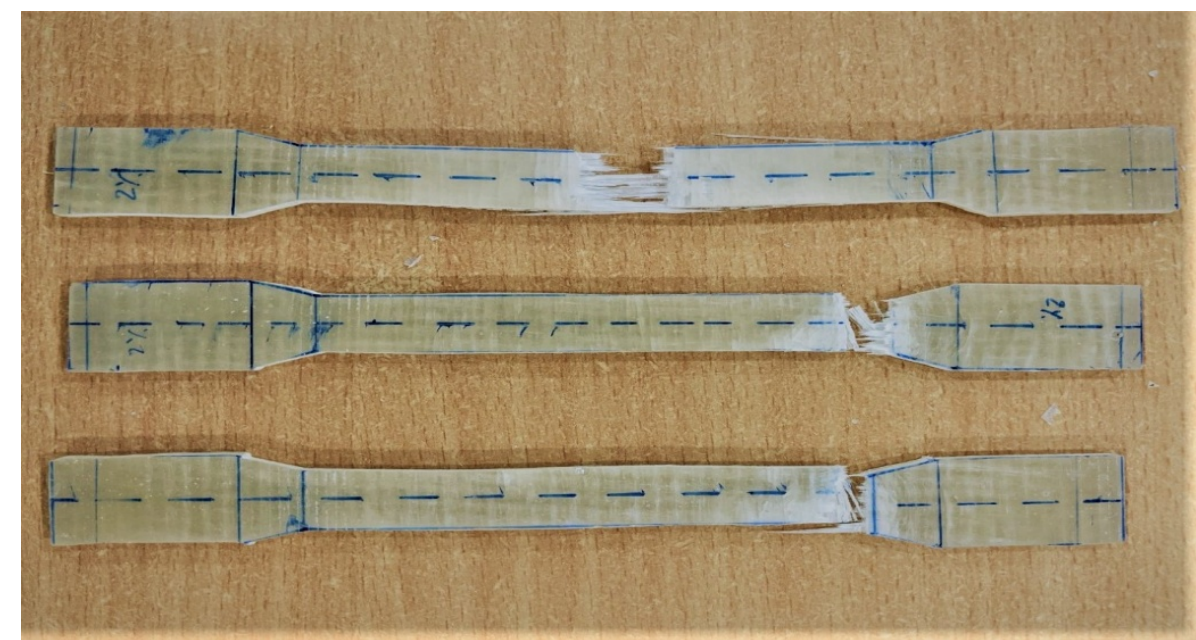

Figure 2: Test specimens After tensile test

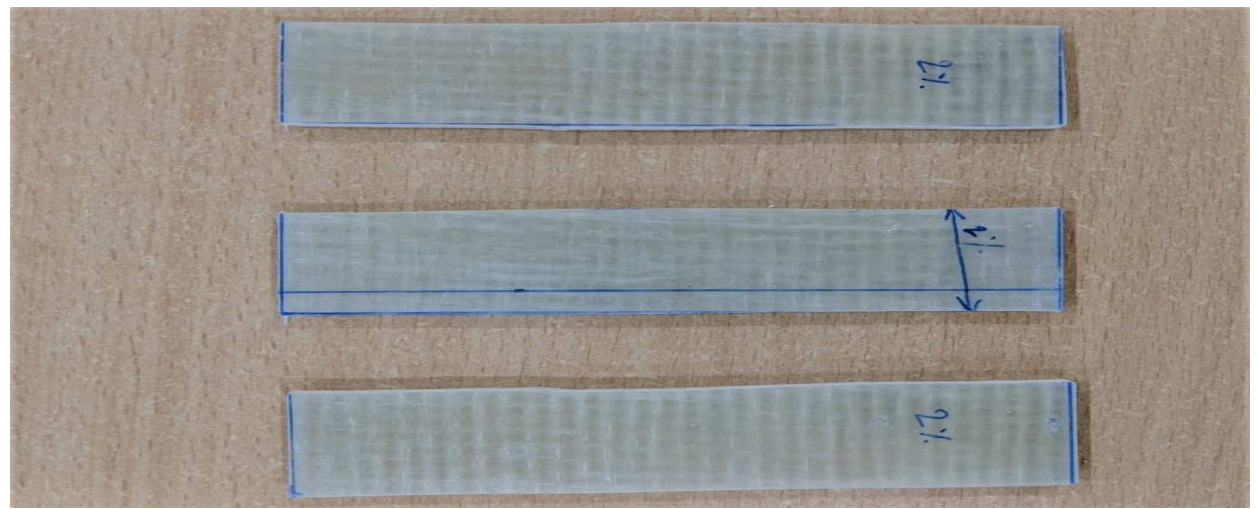

Figure 3: Test specimens Before Flexural test

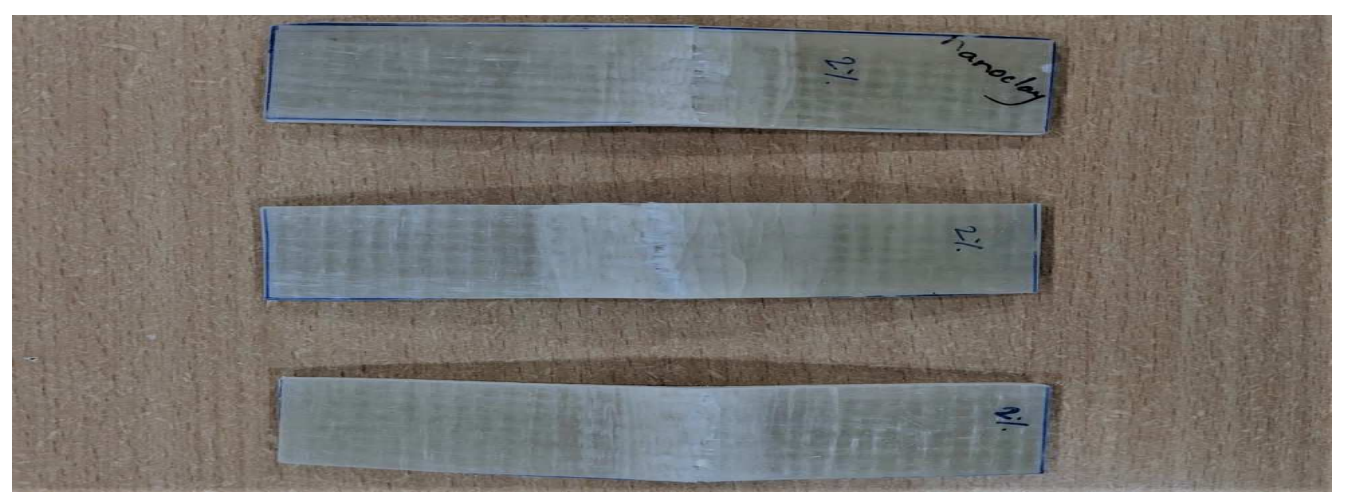

Figure 4: Test specimens After Flexural test

\section{RESULTS AND DISCUSSIONS}

The mechanical properties of S-glass fiber Reinforced Epoxy composites with various nano clay loadings are listed in table 1. Figure 5 shows the impact of nano clay loading on tensile strength and modulus of elasticity. Tensile strength and tensile modulus of composites is increased with addition of nano clay. The expansion in the elasticity and flexural strength with increment of nano clay loading is because of better connection among filler and matrix and the drop in tensile and flexural strength with further expansion of filler beyond $1 \mathrm{wt} \%$ is the way that there is more fiber matrix connection than that of filler-matrix connection. With expansion of $1 \mathrm{wt} \%$ of nano clay into epoxy, the tensile and flexural strength is expanded contrasted with without nano clay S-glass reinforced Epoxy composite. 
Table 3: Mechanical Properties of different Wt\% of Nano clay

\begin{tabular}{|c|c|c|c|c|c|c|}
\hline \multirow{2}{*}{$\begin{array}{c}\text { Composite with } \\
\text { weight \% of nano } \\
\text { clay }\end{array}$} & \multicolumn{3}{|c|}{ Tensile properties } & \multicolumn{3}{c|}{ Flexural properties } \\
\cline { 2 - 7 } & $\begin{array}{c}\text { Tensile } \\
\text { strength } \\
{[\mathrm{Mpa}]}\end{array}$ & $\begin{array}{c}\% \\
\text { elongation }\end{array}$ & $\begin{array}{c}\text { Modulus of } \\
\text { elasticity } \\
{[\mathrm{Mpa}]}\end{array}$ & $\begin{array}{c}\text { Flexural } \\
\text { strength } \\
{[\mathrm{Mpa}]}\end{array}$ & $\begin{array}{c}\text { Flexural } \\
\text { Strain\% }\end{array}$ & $\begin{array}{c}\text { Flexural } \\
\text { modulus }\end{array}$ \\
\hline $0 \%$ & 156.922 & 4.6 & 5604 & 359.110 & 11.6 & 25.250 \\
\hline $1 \%$ & 160.512 & 5.1 & 5773 & 423.110 & 12.8 & 29.750 \\
\hline $2 \%$ & 154.102 & 4.5 & 5171 & 383.999 & 14.9 & 26.996 \\
\hline $3 \%$ & 134.033 & 4.6 & 5077 & 305.777 & 13.8 & 21.510 \\
\hline
\end{tabular}
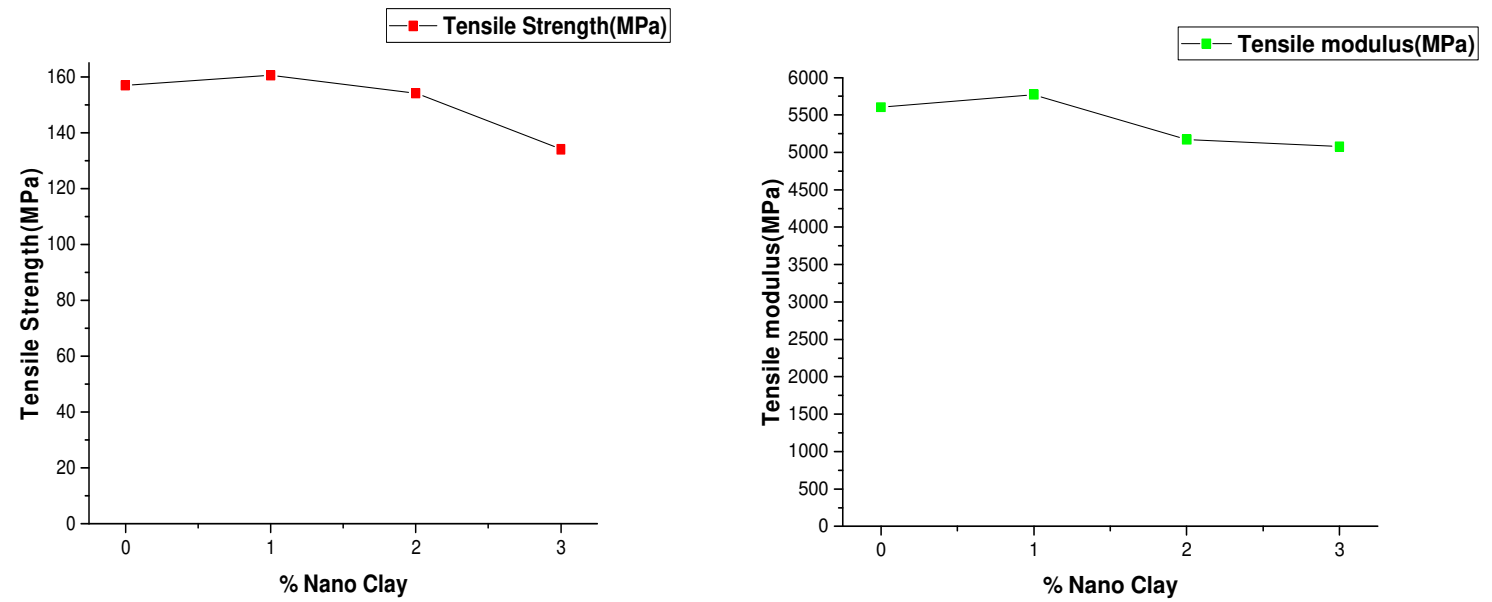

Figure 5: Effect of Nano clay loading on tensile strength and modulus of elasticity
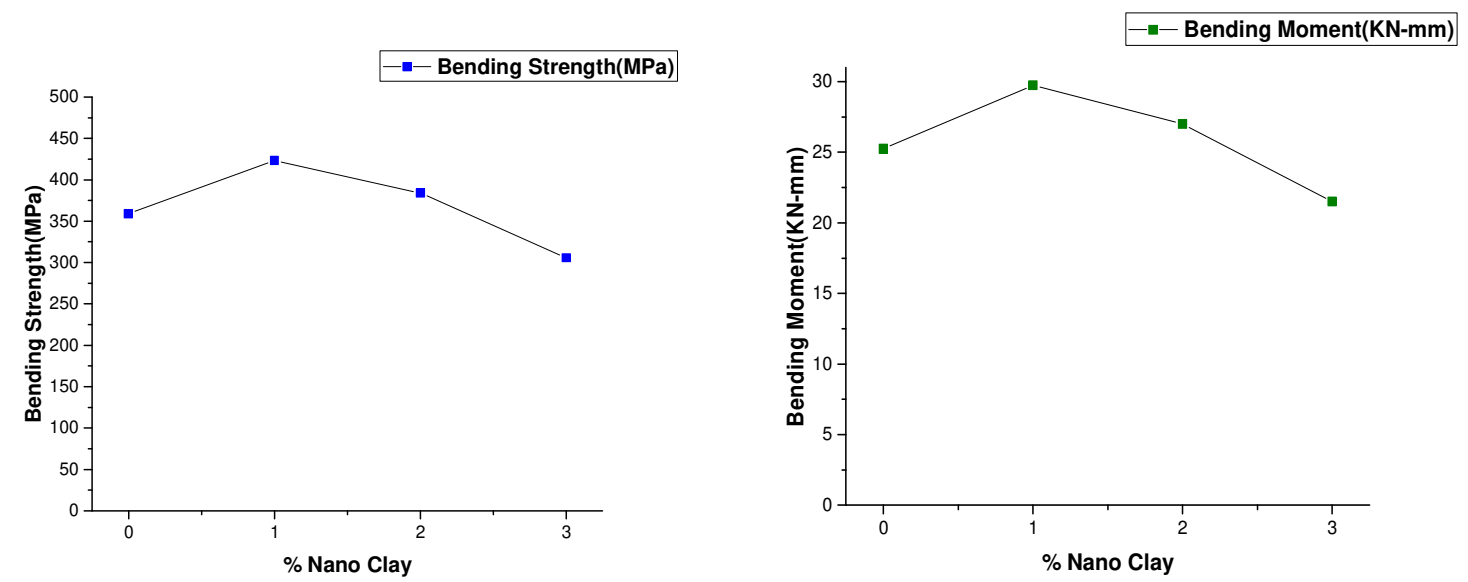

Figure 6: Effect of Nano clay loading on Flexural strength and Flexural modulus

\section{CONCLUSIONS}

The impact of nano clay loading on mechanical properties of S-glass fiber reinforced Epoxy composites was examined in this investigation. Adding of $1 \mathrm{wt} \%$ of nano clay by weight indicated the most extreme elastic strength (160.512 Mpa) which is higher than the composite without nano clay. The flexural test shows that the including of 1 wt $\%$ of nano clay by 
weight into matrix gives the greatest flexural strength (423.110 Mpa), which is higher than the composite without nano clay. The drop in tensile and flexural strength with further expansion of filler beyond $1 \mathrm{wt} \%$ is the way that there is more fiber matrix association than that of filler-matrix connection. At last, itis reasoned that there is an important role of adding nano clay in improving the quality of the composite.

\section{REFERENCES}

1. M. Somaiah Chowdary and M.S.R Niranjan Kumar (2015), Effect of Nano clay on the Mechanical properties of Polyester and S-Glass Fiber (Al) IJAST, Vol.74 (2015), pp.35-42.[2] P. Srinivas Manikanta, M. Somaiah Chowdary, Evaluation of Mechanical Properties of Banana and S-glass Fiber-Reinforced Hybrid Nanosilica Composite, doi.org/10.1007/978-981-151201-8_83

2. I.M. De Rosa, F. Marra, G. pulci, C. Santulli, F. Sarasini, J. Tirillo, M. Valente, (2011) "post impact mechanical characterization of E-Glass/basalt Woven Fabric interplay hybrid laminates", Express polymer Letters, 5(5):449-459

3. J. Njuguna, K. Pielichowski, s. Desai, Nano filler reinforced polymer Nano composites. Polym Advan. Technol. 19(8) (2008) 947-959

4. Kurimoto M. et al. (2007). "Improvement of Dispersibility Of Nano Fillers in Epoxy/Alumina Nano composite by Application of Ultrasonic Wave”,Proceedings of International Symposium on Eco Topia Science, ISET

5. K. Deepak, N.S. Reddy, T.S. Naidu. "Thermosetting Polymer and nano clay based natural fiber bio-composites”. Proce Mater Sci.10(2015)626-631.

6. R. Jeyakumar, P. S. Sampath. Structural, morphological and mechanical behaviour of glass

7. fibre reinforced epoxy Nano clay compositesDOI 10.1007/s00170-017-0565-x

8. Guo g, Park C, Lee Y, Kim Y, Sain M (2007) "Flame retarding effects of nano clay on wood-fiber composites. Polym. Eng. Sci 47(3):330-336

9. Do Rigato A, Morandi S, pegoretti A (2011) Effect of nano clay addition on the fiber/matrix adhesion in epoxy/glass composites. J Compos Mater 46(12):1439-1451

10. Kundan Patel, Jay Patel, Piyush Gohil, Vijay Kumar Chaudhary "Effect of Nano clay on Mechanical Behaviour of Bamboo Fiber Reinforced Polyester Composites. ISSN:1662-7482, Vol.877, pp294-298 

